\title{
A PSICODINÂMICA DO DEPENDENTE DE SUBSTÂNCIAS PSICOATIVAS
}

\author{
Luís Sérgio Sardinha*, Cibele Pombo de Moraes** \\ Autor correspondente: Luís Sérgio Sardinha. E-mail: sergiolss@ymail.com \\ * Docente na Universidade Anhanguera de São Paulo - UNIAN-SP \\ ** Estudante de graduação na Universidade Anhanguera de São Paulo - UNIAN-SP
}

\begin{abstract}
Resumo
O trabalho teve como objetivo compreender como ocorre o funcionamento da psicodinâmica do indivíduo dependente de substâncias psicoativas, procurando entender o significado da substância na vida deste sujeito. Por meio de levantamento bibliográfico foi possível verificar importantes características deste dinamismo psíquico do indivíduo dependente. A partir da análise deste material, pode-se observar que o sujeito dependente de substâncias psicoativas possui um déficit no funcionamento psíquico, o que faz com que este não saiba lidar com as frustrações e angústias oriundas das situações do cotidiano, recorrendo às drogas como consolo para seus sofrimentos. Ressalta-se aqui o papel das figuras materna e paterna no desenvolvimento psíquico deste sujeito. No entanto, a relação própria entre indivíduo e substância psicoativa só pode ser conhecida mediante a escuta de cada discurso singular dos sujeitos dependentes.

Palavras-chaves: Dependência; Substâncias Psicoativas; Drogas; Toxicomania e Psicodinâmica.
\end{abstract}

\section{THE PSYCHODYNAMICS OF SUBSTANCE-DEPENDENT}

\begin{abstract}
This study aims to understand how is the functioning of the individual psychodynamic dependent on psychoactive substances, trying to understand the meaning of the substance in the life of this guy and what the void occupied by it. Through literature rose some important aspects about the individual dependent. From the analysis of this material, it can be observed that the subject dependent on psychoactive substances has a deficit in the functioning of the ego, which means it does not deal with any frustrations and anxieties arising from your psyche and routine general, resorting to drugs as consolation for their sufferings. We emphasize here the role of maternal and paternal figures in psychic development of this subject. However, the relationship between individual and psychoactive substance will only be known by listening to each speech of singular dependent subjects.
\end{abstract}

Keywords: Addiction; Psychoactive Substances; Drugs and Psychotherapy. 


\section{INTRODUÇÃO}

Desde os primórdios até os dias de hoje, as drogas são utilizadas pelos indivíduos para diversas finalidades, podendo ser definida como uma substância que produz algum efeito no organismo seja este benéfico ou maléfico. Segundo o Observatório Brasileiro de Informações sobre Drogas (OBID) ${ }^{(1)}$ o termo droga tem sua origem derivada do holandês antigo, que faz referência à folha seca, visto que muitos medicamentos levavam vegetais em sua fórmula. Já a Organização Mundial de Saúde (OMS) ${ }^{(2)}$ entende que esta consiste em qualquer substância não produzida pelo organismo cuja atuação ocorra em um ou mais sistemas produzindo alterações em seu funcionamento.

Dentre as drogas existentes podem ser encontradas as substâncias psicoativas, que são definidas como substâncias cuja ação principal ocorre no Sistema Nervoso Central - SNC, provocando a alteração do comportamento, do humor e da cognição(2) ${ }^{(2 i t a d o ~ p e l o ~ I n s t i t u t o ~ d e ~ M e d i c i n a ~ S o c i a l ~ e ~}$ de Criminologia (IMESC - INFOdrogas). ${ }^{(3)}$ Estas podem ser divididas em três grupos de acordo com a principal atividade que exercem em nosso SNC, estas atividades podem ser depressoras, estimulantes ou perturbadoras (Centro Brasileiro de Informações sobre Drogas Psicotrópicas (CEBRID). ${ }^{(4,5)}$

As substâncias depressoras do SNC apresentam, como principal efeito, induzir a um funcionamento do cérebro de forma mais lenta, fazendo com que haja a redução da atividade motora, atenção e concentração. Já as substâncias estimuladoras do SNC, apresentam, como principal característica, exacerbar a atividade cerebral. As substâncias perturbadoras do SNC tem, como principal efeito, a produção de distorções no funcionamento cerebral. $(4,5)$

O uso contínuo destas substâncias pode levar o indivíduo a desenvolver dependência. Segundo a $\mathrm{OMS}^{(2)}$ a dependência de substâncias psicoativas é caracterizada por um conjunto de fenômenos fisiológicos, comportamentais e cognitivos no qual o uso de uma substância ou classe de substâncias alcança uma prioridade muito maior para um determinado indivíduo que outros comportamentos que antes tinham maior valor. Uma característica descritiva central da síndrome de dependência é o desejo (frequentemente forte, algumas vezes irresistível) de consumir drogas. Nesta mesma linha de pensamento, a American Psychological Association (APA) ${ }^{(6)}$ entende a dependência de substâncias psicoativas como um padrão mal adaptativo do uso de substâncias, levando a prejuízo ou a sofrimento clinicamente significativos, quando isto ocorre num período de até doze meses após a última utilização.

Com o passar dos anos o consumo de substâncias psicoativas vem aumentando. Já na década de 90 do Século Passado, aponta Mota, ${ }^{(7)}$ estudos indicavam que o consumo de substâncias psicoativas seria considerado um dos 20 fatores de risco para problemas de saúde. Segundo o Instituto $\mathrm{Na}$ cional de Políticas Públicas de Álcool e Drogas ${ }^{(8)}$ no estudo denominado "II Levantamento Nacional sobre Álcool e Drogas - LENAD”, aproximadamente 1,3 milhões de pessoas é dependente de maconha no Brasil. Este mesmo estudo mostra que - Brasil representa o segundo maior mercado de cocaína do mundo em razão do número absoluto de usuários e é considerado o maior mercado de crack do mundo. Quanto ao consumo de álcool foi constatado que os índices de uso abusivo e dependência eram altos entre os bebedores. Além destes dados estatísticos, a dependência de substâncias psicoativas pode ser entendida do ponto de visto psicológico e psicodinâmico.

Para Freud (1930) citado por Ribeiro, ${ }^{(9)}$ o recurso às drogas é entendido como uma resposta possível do sujeito ao mal estar que é inerente tanto ao processo de formação das sociedades e culturas como também à própria constituição psíquica do ser humano. Assim a droga seria uma suspensão da existência frente à dor de existir, isto é, seria uma forma de suportar o conflito e proteger-se do mesmo. Vale ressaltar que Freud não propôs nenhuma teoria acerca das toxicomanias e adicções. 
A toxicomania contempla, segundo Olievenstein (1989) citado por Ribas, ${ }^{(10)}$ uma situação psicoafetiva estruturada, buscando encontrar um estado almejado, que deve funcionar como euforizante das satisfações que o indivíduo não encontra na vida cotidiana. Já o termo adicção remete-se em sentido mais amplo à dependência de substâncias que atuam principalmente no SNC. ${ }^{(1)}$ Assim, todos estes termos citados podem ser usados como sinônimos da dependência de substâncias psicoativas.

Assim como propôs Freud citado por Pimenta ${ }^{(12)}$ refere que a toxicomania e a melancolia bebem da mesma fonte metapsicológica. Um paciente que se apresenta, em um primeiro momento, como "dependente químico", à medida que a clínica avança, se pode perceber que sob a máscara da toxicomania, repousa um sujeito que padece de uma tristeza e de uma posição melancólica, que seria uma posição profundamente dolorosa, com perda de interesse pelo mundo exterior, capacidade de amar e inibição do amor próprio.

Ribas $^{(10)}$ entende o desenvolvimento de uma toxicomania como um movimento defensivo, a fim de sanar os sintomas depressivos das frustrações e as ansiedades decorrentes do "não". Assim, o mesmo autor afirma que todas as toxicomanias são atitudes defensivas do ego contra a manifestação de sintomas depressivos. Isto é confirmado por Gebsattel (1948) citado por Ribas ${ }^{(10)}$ ao referir-se a este "vazio" ocupado pela droga de "desespero".

Autores como Costa ${ }^{(13)}$ explicam a dificuldade do adicto em ingressar na posição depressiva visto que a droga funciona como um escape para que este não entre nesta posição, assim o dependente tenta preencher com objetos reais (droga) a falta de seu desejo com a intenção de acabar com sua insatisfação.

Kessler ${ }^{(14)}$ aponta que na relação do dependente com suas figuras parentais bem como em todas as suas relações objetais estabelecidas o sentimento de ambivalência irá permea-lás, ou seja, ao mesmo tempo em que este pede a atenção e o amor de uma figura materna, este a rejeita sendo a mesma atitude empregada em relação às drogas, o prazer momentâneo que ela causa em contrapartida com o prejuízo adquirido pela mesma.

Ainda com relação à figura materna, Olievenstein $^{(14)}$ diz que a mãe insuficientemente boa geraria um estado de crônica falta. Assim o depender de drogas seria o resultado do deslocamento deste sentimento de falta para uma "coisa". No caso a droga. No que se refere à figura paterna, Costa ${ }^{(13)}$ também o papel desta figura "insuficientemente boa" estar relacionada ao início de uma possível dependência de substâncias psicoativas.

Assim, com esta pesquisa bibliográfica muitos questionamentos podem ser levantados acerca desta temática, como por exemplo: será a droga capaz de ocupar um vazio deixado por algum sentimento? Será a droga produto de uma estrutura familiar deficiente? Em resposta a estas perguntas, este trabalho teve como proposta entender melhor o funcionamento da psicodinâmica do indivíduo dependente de substâncias psicoativas.

\section{MÉTODO}

$\mathrm{Na}$ tentativa de compreender os questionamentos apresentados foi realizado um levantamento bibliográfico. Segundo $\mathrm{Gil}^{\left({ }^{(15)}\right.}$ a pesquisa bibliográfica é desenvolvida com base em material já elaborado, constituído principalmente de livros e artigos científicos. Assim, foram levantados artigos científicos e literaturas já existentes de cunho psicanalítico sobre o tema dependência de substâncias psicoativas, tomando as precauções de serem referências publicadas a partir do Ano 2000. Estas foram retiradas das plataformas disponíveis nos sites Scielo e Biblioteca Virtual em Saúde (BVS).

A triagem dos textos deu-se por meio da utilização das seguintes palavras-chaves: dependência, substâncias psicoativas, drogas, toxicomania e psicodinâmica do dependente. Anterior à seleção dos textos, foi definido o tema, o objetivo e o problema de pesquisa já anteriormente citada. Em seguida realizou-se o plano de pesquisa a fim de nortear sua escrita. Os resultados, discussões e conclusões são apresentados. 


\section{DESENVOLVIMENTO}

Durante o levantamento bibliográfico, foram encontrados 23 artigos científicos, sendo que 12 destes artigos foram utilizados para compor o presente trabalho e 11 artigos não foram utilizados. Os 12 artigos foram selecionados segundo seu conteúdo, de cunho psicanalítico voltado para o sujeito dependente de substâncias psicoativas e baseado nas palavras chave determinadas e acima mencionadas: dependência, substâncias psicoativas, drogas, toxicomania e psicodinâmica. Os demais artigos não puderam ser utilizados para este trabalho, pois se relacionavam aos aspectos psicanalíticos das famílias do sujeito dependente de substâncias psicoativas, ao surgimento da codependência, à análise dos modelos de intervenção e abordagem adotados no tratamento destes indivíduos e as consequências da dependência. Questões importantes, relacionadas ao tema proposto, mas que não eram diretamente abordadas neste momento. A seguir os conteúdos dos 12 artigos são apresentados.

Segundo $\operatorname{Costa}^{(13)}$ e $\operatorname{Mota}^{(7)}$ a dependência de drogas é uma doença multifatorial, sendo uma combinatória de fatores biológicos, sociais e psicológicos. Os fatores biológicos, conforme Costa ${ }^{(13)}$ referem-se à questão genética que é própria de cada organismo, podendo apresentar genealogia positiva para dependência de drogas e vulnerabilidade ao efeito de drogas. Com relação aos fatores sociais e culturais, Kessler ${ }^{(14)}$ nos mostra alguns fatores de risco como: a permissividade social, a disponibilidade de droga e a privação econômica.

Em relação aos fatores psicológicos que levam o indivíduo ao uso abusivo de substâncias psicoativas, Freud (1930) citado por Ribeiro ${ }^{(9)}$ afirma que o recurso às drogas é entendido como uma resposta possível do sujeito ao mal estar que é inerente tanto ao processo de formação das sociedades e culturas quanto à própria constituição psíquica do ser humano. Diante dessa pressão exercida pela civilização e pelas instâncias repressoras do psiquismo, instaura-se um mal-estar que apenas pode ser suportado por meio do que Freud designou de medidas paliativas. Dentre as medidas paliativas exis- tentes, este considerou o recurso aos tóxicos como o método mais grosseiro, embora também o mais eficaz para evitar o sofrimento humano, pois influencia o nosso corpo e altera sua química de forma a nos tornar insensíveis à nossa desgraça conforme relata Freud (1930) citado por Ribeiro. ${ }^{(16)}$

A intoxicação seria um tipo de defesa contra o sofrimento que procura dominar as fontes internas de nossas necessidades e a intoxicação crônica é uma forma extrema disso que leva ao aniquilamento das pulsões. Para Lacan (1976) citado por Ribeiro(16) a importância que os tóxicos adquirem para cada um passa a ser atribuída fundamentalmente ao lugar que eles vêm a ocupar na economia psíquica daquele que faz da intoxicação uma prática. Esta afirmação é complementada por Santiago (2001) citado por Ribeiro(16) no qual se torna necessário situar, precisamente, o lugar que a droga ocupa no modo particular de satisfação de um sujeito determinado".

Assim, segundo Ribeiro ${ }^{(16)}$ somente por meio de uma escuta do que o indivíduo tem a dizer sobre sua relação com os tóxicos e sobre como ele entende que estas o ajudam a lidar com o mal-estar inerente à sua condição humana que se pode identificar o lugar que a droga ocupa na subjetividade do paciente. Gianesi ${ }^{(17)}$ também coloca que cada sujeito dito toxicômano apresenta sua particular relação com o objeto droga dentro de sua estrutura.

De acordo com Nogueira (2006) citado por Bersani(18) a droga é um significante que ocupa um lugar para o sujeito que faz uso dela bem como para cada membro da família. Já para Olievenstein (1990) citado por Kessler ${ }^{(14)}$ o uso de substâncias psicoativas estaria ligado a um sentimento de falta, o qual seria aliviado por elas. Com isso, a dependência se configuraria no deslocamento deste sentimento de falta para uma "coisa", que estaria ao fácil alcance dos indivíduos.

Considerando a relação particular entre indivíduo e substância, Pimenta ${ }^{(12)}$ colocam que a toxicomania e a melancolia bebem da mesma fonte metapsicológica ao analisar um paciente dito em um primeiro momento como dependente químico e a 
medida que o tratamento avança percebe-se uma tristeza e uma posição melancólica, que leva a uma expectativa de castigo e a depressão. Nesta mesma relação entre a toxicomania e a melancolia, Caravelli(19) relata a droga como um recurso, matéria-prima que, apesar da inadequação, faz valer sua condição anestésica, no qual o sujeito atribui a ela, a função de selar seu vazio, coagular sua hemorragia narcísica e aliviar sua dor de existir.

Estas ideias podem ser embasadas pelo conceito de "moldura vazia" citada por Lambotte (1997) citado por Caravelli, ${ }^{(19)}$ na qual o bebê não se sente o objeto de desejo da figura materna, assim esse olhar vazio terá a condição de dar ao sujeito um estado de existência e não de atribuição, fazendo com que este carregue uma marca identificatória com o nada. Freud (1926/1992) citado por Pimen$\mathrm{ta}^{(12)}$ se refere ao conceito de "moldura vazia" como uma situação de desamparo, na qual o bebê ainda é absolutamente dependente de sua figura materna para sobreviver, mas se encontra confrontado com uma ausência materna, fazendo com que haja a perda de seu objeto de amor mesmo sem a sua simbolização.

Pimenta ${ }^{(12)}$ afirma que essa situação de desamparo irá acompanhar o sujeito por toda a sua vida e é para lidar com esta, que surge a substância psicoativa. Em virtude disso, o toxicômano enfrenta dificuldades ao encarar a falta, assim apresenta uma maneira intensa de se relacionar com seus objetos, não deixando espaço à falta e à perda, passando de um objeto de dependência a outro. Assim dá-se o movimento de repetição em busca da substância. A repetição relaciona-se à falta e esta ao objeto, fazendo com que o indivíduo tente reencontrar o objeto perdido. ${ }^{(17)}$

Ribas(9) também colocam que todas as toxicomanias são atitudes defensivas do ego contra a manifestação de sintomas depressivos. Para este mesmo autor, a estrutura de personalidade do dependente de substâncias psicoativas possui menos recursos psíquicos para lidar com as frustrações e com as ansiedades do cotidiano, assim a droga teria por função ocupar o lugar de sua intolerância às frustrações, configurando-se em uma busca pelo prazer e pela felicidade, no entanto de curto espaço de tempo. Outro ponto a ser discutido com relação à dependência de substâncias psicoativas é o papel da figura materna na realidade psíquica do dependente conforme ressalta Kessler. ${ }^{(14)}$

A relação entre sujeito dependente e imagem materna é dominada por sentimentos de ambivalência que são estendidos a sua relação com as substâncias e as suas outras relações objetais. As sim, ao mesmo tempo em que o dependente clama pelo amor objetal de uma figura materna, ele o despreza. Como consequência da ambivalência, a criança não é capaz de introjetar a imagem desta figura, o que leva a uma falta das funções de autocuidado.

Klein (1940) citado por Ribas ${ }^{(10)}$ entende que ocorreu uma separação exageradamente hostil da criança em relação ao seio materno, isso fez com que o ego do toxicômano se estruturasse com excessiva divisão de objetos idealizados e ao mesmo tempo, denegridos fazendo com que haja dificuldades de ingresso na posição depressiva, fixando o sujeito na posição esquizoparanóide. Assim a droga simbolizaria o objeto ideal que pode ser concretamente incorporado, no entanto não funciona como parceiro dual, por isso o sentimento de abandono e de rejeição continua presente no toxicômano.

Ainda com relação às figuras parentais, Kohut (1972) citado por Kessler ${ }^{(14)}$ reafirma que as funções paterna e materna encontram-se comprometidas. A personalidade do dependente encontra-se privada de coesão, necessitando de algo para unir estas partes, já que faltou a identificação com a figura paterna e a empatia com a figura materna. É nesta falta que a droga entra. ${ }^{(12)}$

Além disso, Winnicott citado por Kessler ${ }^{(14)}$ ressalta que as figuras maternas não suficientemente boas gerariam um estado de crônica falta, esta que seria oceânica e jamais saciável. No que tange a figura paterna $\operatorname{Costa}^{(13)}$ afirma que a figura paterna assinala seu lugar como significativo e posiciona o lugar da figura materna e do filho. Isso faz com que 
haja duas interdições: a figura materna deixa de ser vinculada com a família de origem e mostra o lugar do filho à medida que este castra o acesso genital à mãe. ${ }^{(10)}$

Assim conforme Ribas ${ }^{(10)}$ o pai pode intervir nessa relação mãe-filho, porém não o suficientemente forte para assumir o seu próprio lugar (interdição) configurando-o como impotente ou segundo Costa ${ }^{(13)}$ o pai pode abster de seu lugar e de sua função não servindo com um modelo de identificação para o filho, que passa a não conhecer a aquisição de limites. Com isso, sua relação com a lei passa a ser transgressora conforme relata Olievenstein (1983) citado por Ribas. ${ }^{(10)}$

Com isso, a figura paterna que não promove um modelo de identificação com o filho, não estabelece limites de relações e não evidencia o lugar da figura materna, do filho e da figura paterna, pode vir a prejudicar a configuração essencial para o bom desenvolvimento psíquico. Segundo Costa ${ }^{(13)}$ o pai "insuficientemente bom" pode estar relacionado ao início de uma possível dependência de substâncias psicoativas. $O$ apelo à figura paterna é um pedido de interdição, quando esta falha, surge o sintoma, que é sanado pelo uso da droga que tem por função restituir esta figura paterna.

Enfim, o dependente traz consigo o modelo familiar internalizado durante sua infância e pelo qual irá atuar em sua vida, estabelecendo os mesmos vínculos aprendidos com a droga. Como afirma Kalina (1999) citado por Costa(13) o paciente identificado (dependente) representa uma disfuncionalidade da família, trazendo consigo os conflitos familiares a ser representados por ele, sendo uma forma de "mascarar" todas as dificuldades que estão presentes no contexto familiar. $O$ dependente de substâncias psicoativas dispensa o outro como parceiro, pois este é representado pela droga. Ribas ${ }^{(10)}$ também coloca que no momento em que o dependente toma consciência de sua situação, este passa a se deparar com um superego bastante punitivo, exigente e castigador, fato característico de dinâmicas psíquicas depressivas. ${ }^{(5)}$
Portanto a dependência de substâncias psicoativas pode ser considerada como uma tentativa, desesperada, de compensar a baixa autoestima e os déficits de funcionamento do ego conforme Ferreira (1998) citado por Costa ${ }^{(13)}$ nos aponta. No entanto deve ser analisada multifatorialmente, pois como afirma Gianesi ${ }^{(17)}$ cada sujeito toxicômano apresenta sua particular relação com o objeto droga dentro de sua estrutura.

\section{RESULTADOS}

Em resposta aos questionamentos apresentados neste trabalho e aos apontamentos levantados acerca da psicodinâmica do dependente de substâncias psicoativas, grande parte das referências bibliográficas citadas aponta para o fato de que o indivíduo dependente possui um déficit do funcionamento do ego, o que faz com que ele dentro de sua estrutura de personalidade não saiba lidar com as frustrações, ansiedades e angústias advindas do seu próprio funcionamento psíquico e da realidade. Com isso, o sujeito utiliza a droga para suportar esses dissabores, conforme cita Freud (1929) citado por Ribas ${ }^{(10)}$ a droga seria como um "quebra-desgosto", colocada pela natureza à disposição do homem para este se consolar dos seus sofrimentos e se recuperar de seus fracassos.

Outra ideia que aparece nos estudos citados é o fato de que a substância psicoativa venha a preencher no dependente um vazio nele instaurado. Assim, a droga entra no vazio que ele sente na falta que ele apresenta conforme ressaltado por Kessler, ${ }^{(14)}$ ao afirmar que o depender de drogas seria o resultado do deslocamento deste sentimento de falta para uma coisa, com a vantagem de esta ser alcançável em qualquer esquina do mundo.

Uma consideração de fundamental importância sobre a dependência de substâncias psicoativas se refere ao papel das figuras parentais no desenvolvimento psíquico do sujeito. Muitos autores apontam que o fato das figuras maternas não serem suficientemente boas gerariam no indivíduo um estado de falta que implica na busca de medidas 
paliativas para suportar esse sentimento de abandono. A figura paterna também é por muitas vezes citada como essencial na construção do psiquismo do sujeito, pois exerce o papel de autoridade, daquele que estabelece os limites a serem seguidos conforme refere Winnicott (1982) citado por Costa $^{(13)}$ ser o pai o ser necessário para dar apoio moral à mãe; ser um ser humano que sustenta a lei e a ordem que a mãe implanta na vida da criança.

No entanto, as diferentes pulsões que levam o sujeito a usar substâncias psicoativas e delas depender, só serão conhecidas por meio da análise e escuta singular de cada indivíduo toxicômano, pois como afirma Gianesi ${ }^{(17)}$ a droga e seu uso assumem diversas faces dentre de cada discurso.

\section{CONSIDERAÇÕES FINAIS}

O objetivo deste trabalho foi compreender o funcionamento da psicodinâmica do indivíduo dependente de substâncias psicoativas, procurando entender qual o significado da substância na vida do sujeito e qual o vazio por ela ocupado. Por meio de revisão bibliográfica foi evidenciado que a droga é um recurso, mesmo que paliativo, que o indivíduo utiliza como consolo e refúgio para seus aborrecimentos advindos de seu próprio funcionamento psíquico e da sua rotina em geral, visto sua dificuldade em lidar com as angústias e frustrações. Além disso, foi verificada a importância das figuras parentais frente ao indivíduo dependente, descrevendo que se caso a figura materna não tenha sido suficientemente boa, isso poderia gerar um estado de falta no sujeito que desencadearia a procura por recursos substitutos, no caso a droga. Já a figura paterna seria responsável pelo estabelecimento de limites e regras fundamentais no desenvolvimento psíquico do indivíduo.

Observou-se também que a relação estabelecida entre o dependente e a substância é única, podendo somente ser compreendida por meio da escuta e análise de cada discurso. Esta situação aponta para a complexidade do tema. Se espera que assim como este trabalho pode levantar alguns aspectos importantes do funcionamento psíquico do dependente, outros trabalhos possam ser realizados, no intuito de entender o significado que a droga assume na vida dos indivíduos, visto o crescente número de pessoas dependentes de substâncias psicoativas atualmente.

\section{REFERÊNCIAS}

1. Observatório Brasileiro de Informações sobre Drogas . Disponível em: http://www.obid.senad. gov.br/portais/OBID/index.php

2. Organização Mundial da Saúde, coordenador. Classificação de transtornos mentais e de comportamento da CID-1O: descrições clínicas e diretrizes diagnósticas. Trad. Dorgival Caetano. Porto Alegre: Artes Médicas; 1993.

3. Instituto de Medicina Social e de Criminologia. São Paulo, $2 \mathrm{Ol} 2$ [acesso em 13 abr. 2014]. Disponível em: http://www.imesc.sp.gov.br/ infodrogas/Psicotro.htm

4. Centro Brasileiro de Informações sobre Drogas Psicotrópicas. Disponível em: http://www.unifesp. br/dpsicobio/cebrid/folhetos/drogas_htm

5. Sardinha LS. As emoções de dependentes de drogas: estudo através do Rorschach. In: Anais do V Encontro da Associação Brasileira de Rorschach e Métodos Projetivos; 2008; Ribeirão Preto, Brasil. Ribeirão Preto: ASBRo; 2008. v. 1. p. 549-558.

6. American Psychiatric Association. DSM-IV-TR Manual diagnóstico e estatístico de transtornos mentais. $4^{\mathrm{a}}$ ed. rev. Porto Alegre: Artes Médicas; 2002.

7. Mota BCD. Avaliação da implementação das políticas públicas sobre o álcool e outras drogas em nível municipal. Belo Horizonte: Centro de Pesquisa, Intervenção e Avaliação em Álcool e Outras Drogas; 2011 [acesso em 13 abr. 2014]. Disponivel em: http://www.ufj.br/crepeia/ files/2009/09/avaliacao-implementacaopoliticas-publicas.pdf

8. Instituto Nacional de Políticas Públicas do Álcool E Drogas. II Levantamento Nacional de Álcool e Drogas - LENAD. São Paulo; 2012 
[acesso em O4 abr. 2Ol4]. Disponível em: http:// inpad.org.br/lenad

9. Ribeiro CT. Que lugar para as drogas no sujeito? Que lugar para o sujeito nas drogas? Uma leitura psicanalítica do fenômeno do uso de drogas na contemporaneidade. Revista Ágora.

2009 [acesso em 13 abr. 2014].;12(2). Disponível em: http://www.scielo.br/scielo.php?script=sci_art text\&pid=S1516-14982009000200012

1O. Ribas VR, et al. Personalidade do dependente químico. Revista de Neurobiologia. 2009 [acesso em 28 abr. 2014];72(3):65-73. Disponível em: http://www.neurobiologia.org/ex_2009.3/ Revista\%2ONeurobilogia-72(3)2009\%2O (Cap.7)(OK).pdf

11. Bento VES. Para uma semiologia psicanalítica das toxicomanias: adiç̧ões e paixões tóxicas no Freud pré-psicanalítico. Rev. mal estar subj. 2007 [acesso em 17 maio 2014];7(1). Disponível em: <http://pepsic. bvsalud.org/scielo.php?script=sci_arttext\&pid =S1518-61482007000100007>.

12. Pimenta SN, Cremasco MVF, Lesourd S. Clínica da toxicomania: uma expressão melancólica? Rev. latinoam. psicopatol. fundam. 2011 [acesso em 25 abr. 2014];14(2):252-267. Disponível em: http://www.scielo.br/pdf/rlpf/v14n2/O4.pdf

13. Costa CP da. O vínculo com a figura paterna e o desenvolvimento da dependência química em jovens do sexo masculino [trabalho de conclusão de curso]. Porto Alegre: Pontifícia Universidade Católica do Rio Grande do Sul; 2007 [acesso em 11 maio 2014]. Disponível em: http://www.psicologia.pt/artigos/textos/ TLO2OO.pdf

14. Kessler F. et al. Psicodinâmica do adolescente envolvido com drogas. Rev. psiquiatr. 2003 [acesso em 28 abr. 2014];1:33-41. Disponível em: http://www.scielo.br/pdf/rprs/v25s1/aO5v25sl. pdf

15. Gil AC. Como elaborar projetos de pesquisa. São Paulo: Atlas; 2002.

16. Ribeiro CT. Usuário ou toxicômano? Um estudo psicanalítico sobre duas formas possíveis de relação com as drogas na contemporaneidade. Estud. pesqui. psicol. 2011 [acesso em 13 abr. 2014].;1(2):633-647. Disponível em: http://www. revispsi.uerj.br/vlln2/artigos/html/vlln2al7.html

17. Gianesi APL. A toxicomania e o sujeito da psicanálise. Rev. Psychê. 2005 [acesso em 25 abr. 2014]; 9(15). Disponível em: http:// pepsic.bvsalud.org/scielo.php?pid=S1415$11382005000100010 \&$ script=sci_arttext

18. Bersani RAA. Psicanálise e Toxicomania [trabalho de conclusão de curso]. Governador Valadares: Universidade Vale do Rio Doce; 2009 [acesso em 06 maio 2014]. Disponível em: http://www.pergamum.univale.br/ pergamum/tcc/Psicanaliseetoxicomania.pdf

19. Caravelli SAL. Inundação no deserto: a toxicomania pelo viés da melancolia [dissertação]. Rio de Janeiro: Universidade Federal do Rio de Janeiro; 2004 [acesso em 19 abr. 2013]. Disponível em: http://www.psicologia.ufrj.br/ nepecc/files/dissertacao_selenacaravelli.pdf 